\title{
THE PASSAGE OF THE BOMB RADIOCARBON PULSE INTO THE PACIFIC OCEAN
}

\author{
William J Jenkins ${ }^{1} \bullet$ Kathryn L Elder • Ann P McNichol • Karl von Reden \\ National Ocean Sciences Accelerator Mass Spectrometer Facility, Woods Hole Oceanographic Institution, Woods Hole, Mas- \\ sachusetts 02543, USA.
}

\begin{abstract}
We report and compare radiocarbon observations made on 2 meridional oceanographic sections along $150^{\circ} \mathrm{W}$ in the South Pacific in 1991 and 2005. The distributions reflect the progressive penetration of nuclear weapons-produced ${ }^{14} \mathrm{C}$ into the oceanic thermocline. The changes over the $14 \mathrm{yr}$ between occupations are demonstrably large relative to any possible drift in our analytical standardization. The computed difference field based on the gridded data in the upper $1600 \mathrm{~m}$ of the section exhibits a significant decrease over time (approaching 40 to $50 \%$ in $\Delta{ }^{14} \mathrm{C}$ ) in the upper $200-300 \mathrm{~m}$, consistent with the decadal post-bomb decline in atmospheric ${ }^{14} \mathrm{C}$ levels. A strong positive anomaly (increase with time), centered on the low salinity core of the Antarctic Intermediate Water (AAIW), approaches $50-60 \%$ in $\Delta^{14} \mathrm{C}$, a clear signature of the downstream evolution of the ${ }^{14} \mathrm{C}$ transient in this water mass. We use this observation to estimate the transit time of AAIW from its "source region" in the southeast South Pacific and to compute the effective reservoir age of this water mass. The 2 sections show small but significant changes in the abyssal ${ }^{14} \mathrm{C}$ distributions. Between 1991 and $2005, \Delta^{14} \mathrm{C}$ has increased by $9 \%$ below $2000 \mathrm{~m}$ north of $55^{\circ} \mathrm{S}$. This change is accompanied overall by a modest increase in salinity and dissolved oxygen, as well as a slight decrease in dissolved silica. Such changes are indicative of greater ventilation. Calculation of "phosphate star" also indicates that this may be due to a shift from the Southern Ocean toward North Atlantic Deep Water as the ventilation source of the abyssal South Pacific.
\end{abstract}

\section{INTRODUCTION}

Observation of the passage of anthropogenically produced transient tracers into the oceans has provided us with an opportunity to characterize ocean ventilation, circulation, and mixing in new ways. In the simplest sense, the penetration of recently produced tracers such as CFCs or anthropogenic radioisotopes into the ocean basins creates a qualitative visualization of the pathways (e.g. Jenkins and Rhines 1980) and timescales (e.g. Schlosser et al. 2001) associated with water mass formation and fluid motion. As importantly, these observations can be effectively used to diagnose the performance of large-scale ocean models (England and Maier-Reimer 2001; Doney and Hecht 2002) or in inversions aimed at the estimation of oceanic inventories of anthropogenic carbon (McNeil et al. 2003; Waugh et al. 2006). Such tracers offer a range of characteristics including how they enter the ocean, their biogeochemical behavior in the marine environment, their half-lives, and their time history at the sea surface. Consequently, each tracer tells us something different about ocean ventilation and circulation.

Radiocarbon is an important tracer, especially in the Pacific, because the distribution of natural ${ }^{14} \mathrm{C}$ offers information on the longest (century to millennium) timescales in the deep waters (Munk 1966; Craig 1969), while the bomb-produced transient component informs us of processes operating on decadal timescales (Broecker and Peng 1980; Mahadevan 2001; Rodgers et al. 2004). Where the bomb and natural ${ }^{14} \mathrm{C}$ distributions overlap, the story becomes more complex, and strategies for separating these 2 components have been proposed (Broecker et al. 1995; Rubin and Key 2002). Perhaps the most powerful diagnostic, however, is the observation of the temporal evolution of ${ }^{14} \mathrm{C}$ distribution; to a first approximation, the natural component will not vary while the bomb transient necessarily evolves.

The GEOSECS expeditions of the 1970s offered the first large-scale glimpse of the ${ }^{14} \mathrm{C}$ distribution in the Pacific (Bainbridge et al. 1987; Ostlund et al. 1974), which was subsequently mapped in

${ }^{1}$ Corresponding author. Email: wjenkins@whoi.edu.

(C) 2010 by the Arizona Board of Regents on behalf of the University of Arizona

Proceedings of the 20th International Radiocarbon Conference, edited by A J T Jull

RADIOCARBON, Vol 52, Nr 2-3, 2010, p 1182-1190 
greater detail by the World Ocean Circulation Experiment (WOCE) large-scale survey in the 1990s (Key 1996; Key et al. 1996, 2002). After this, the CLIVAR (Climate Variability and Predictability) program has organized a series of repeat section occupations at approximately decadal intervals to monitor climate-induced changes in the ocean and to document the evolution of a number of transient tracers in the water column.

We report here a comparison of $2{ }^{14} \mathrm{C}$ sections taken along $150^{\circ} \mathrm{W}$ in the South Pacific between approximately $20^{\circ} \mathrm{S}$ and $63^{\circ} \mathrm{S}$; one taken in 1991 during the WOCE global survey and one occupied in 2005 as part of the CLIVAR Repeat Hydrography Program. In the next section, we provide a brief description of our methods along with quality control procedures used to establish the fidelity of our results, particularly on decadal timescales. After that, we describe and interpret the observed changes in shallow and intermediate waters. Finally, we show changes in the deep water and attempt to link those to concomitant changes in hydrography.

\section{METHODS}

Samples were collected using standard WOCE protocols whereby water was transferred from rosette-mounted Niskin bottles to 0.5 -L borosilicate bottles with ground glass stoppers and "fixed" with saturated mercuric chloride solution to arrest biological activity (Key 1996). On return to the laboratory, the dissolved inorganic carbon (DIC) was removed in a vacuum system by acidification, sparging with ultrapure nitrogen, cryogenically purified, and stored as $\mathrm{CO}_{2}$ in glass ampoules (McNichol et al. 1994). A portion of this gas was graphitized using hydrogen reduction over iron (Vogel et al. 1987; McNichol et al. 1992), and the graphite pressed into aluminum targets and analyzed by cesium sputtering accelerator mass spectrometry (AMS). The unused sample gas was archived for possible future analysis.

The AMS ${ }^{14} \mathrm{C}$ analyses were standardized against the NIST oxalic acid standards (OXI and OXII), and measurement performance was monitored by regular determinations of secondary ("consensus") standards of varying ${ }^{14} \mathrm{C}$ activity. Since its inception, the laboratory has participated in all of the international intercalibration exercises, the most recent of which is VIRI (Scott et al. 2003), where our intercalibration results consistently fall within the range circumscribed by the major AMS measurement facilities.

Results here are reported in the standard $\Delta^{14} \mathrm{C}$ format (Stuiver and Polach 1977), and the experimental uncertainty, estimated from ${ }^{14} \mathrm{C}$ ion counting statistics, comparison of replicate seawater samples, and reproducibility of primary and secondary standards, is better than $5 \%$ in $\Delta^{14} \mathrm{C}$ on individual samples (Key 1996; Key et al. 1996; Elder et al. 1998).

One challenge when interpreting time-series measurements is to rule out potential drift in analytical standardization as a contributor to observed trends in the data. As an additional precaution, we later remeasured archived gas samples from WOCE stations to check for this. This approach will quantify any changes due to graphitization and AMS analysis. Figure 1 is a plot of just such a comparison for WOCE station P16S $198\left(28^{\circ} 29.8^{\prime} \mathrm{S}, 150^{\circ} 29.9^{\prime} \mathrm{W}, 19\right.$ August 1991) for the same samples measured in 1994 and again in 2007. The average offset (2007-1994) is $-0.95 \pm 1.13 \%$, with a standard deviation of $5.75 \%$. The latter quantity is consistent with our published uncertainties, as its expectation value is $\sqrt{2} \sigma$. As importantly, the remeasurement of the 1991 WOCE samples occurred in the same timeframe as our measurement of the samples from the 2005 occupation of P16S, and identical laboratory and analytical procedures were employed with both sets of samples. In any case, the mean offset obtained from this comparison provides us with a firm upper bound of $2 \%$ on any systematic effects that may contribute to any observed differences between the 2 cruise occupations. 


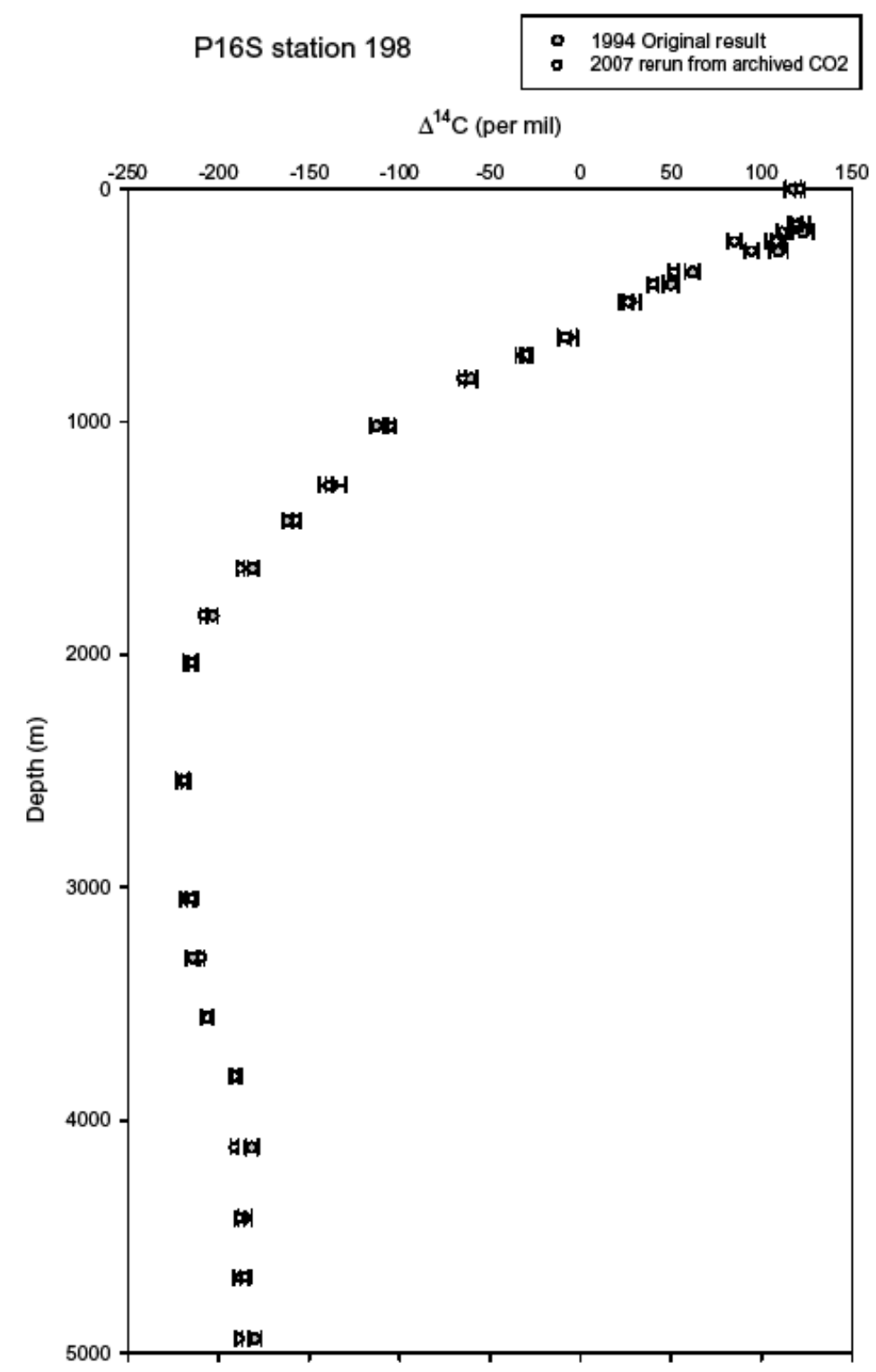

Figure 1 A comparison of WOCE DI ${ }^{14} \mathrm{C}$ measured on a South Pacific WOCE station taken in 1991 measured at 2 points in time: 1994 (filled circles) and 2007 (open circles). The second measurement was made on archived gas splits extracted from the original water samples.

\section{Results and Discussion: Radiocarbon Changes at Shallow and Intermediate Depths}

In Figure 2, we compare the 2 cruises (1991 and 2005). In the top 2 panels of Figure 2, we contour the $\Delta^{14} \mathrm{C}$ (in \%o) and in the third panel, the difference (2005-1991) between the gridded fields as $\Delta \Delta^{14} \mathrm{C}$, again in \%o. In the lowest panel, we show a contour map of salinity (in practical salinity units $=$ PSU) for the section. For the bottom 2 panels, we also show potential density anomaly contours (in $\mathrm{kg} \mathrm{m}^{-3}$ ) overlaid in black. The purpose of the latter is to identify the level associated with 


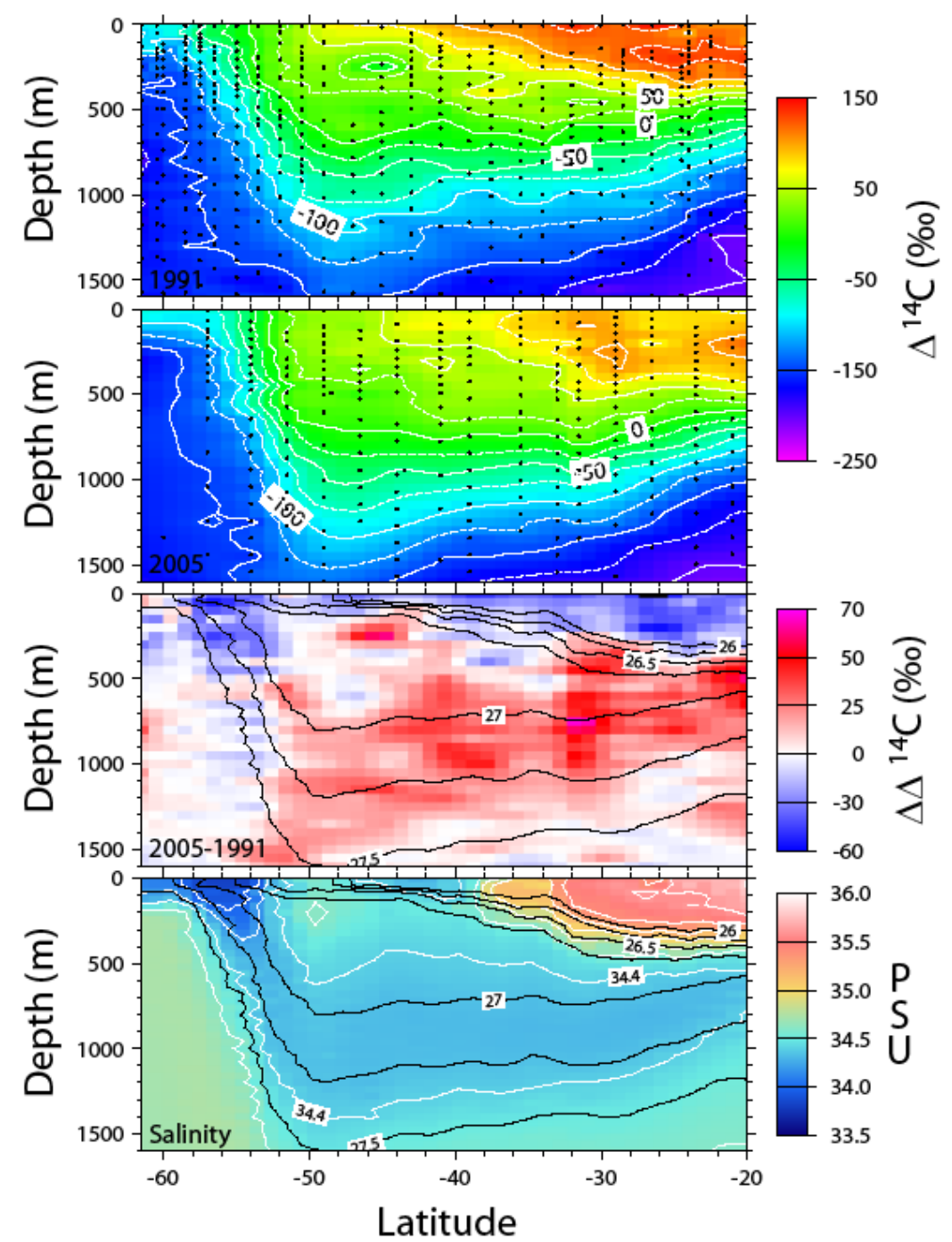

Figure 2 Contour plots (latitude versus depth) of the upper water column distribution of $\Delta{ }^{14} \mathrm{C}$ in 1991 (upper panel) and 2005 (second panel from top), and the difference (2005-1991) between the gridded fields (third panel from top), all in \%o. Sample locations are indicated by black dots in the upper 2 panels. The lowest panel shows the contoured salinity distribution (color map and white contours) with the potential density anomaly (in $\mathrm{kg} \mathrm{m}^{-3}$ ) overlaid as black contours. The potential density anomaly contours are repeated in the ${ }^{14} \mathrm{C}$ difference panel.

the salinity minimum of the Antarctic Intermediate Water that extends downward from the surface at about $56-58^{\circ} \mathrm{S}$, deepening and extending northward at depths near $\sim 1000 \mathrm{~m}$ at $50^{\circ} \mathrm{S}$, shoaling to about $800 \mathrm{~m}$ at $20^{\circ} \mathrm{S}$.

The $2{ }^{14} \mathrm{C}$ sections show similar features, namely a maximum at or near the surface in the subtropics that contrasts with a monotonic decrease in $\Delta^{14} \mathrm{C}$ with increasing depth and latitude. Both sections show a shallow, subsurface ${ }^{14} \mathrm{C}$ maximum equatorward of $30^{\circ} \mathrm{S}$ : a signature of the STC (Subtropical-Tropical Cell) (McCreary and Lu 1994; Liu and Alexander 2007). Similar features are seen in 
meridional sections of both tritium and CFCs, although modified by the space-time character of their introduction into the ocean.

The overall shape of the $\Delta^{14} \mathrm{C}$ distributions (as seen, for example, in the $-100 \%$ contour) mimics the density structure of the subtropical gyre (note the black contours in the lower 2 panels), and reflects the penetration and accumulation of bomb-produced ${ }^{14} \mathrm{C}$ within the thermocline of this oceanographic "province" (Broecker et al. 1985). The $\Delta^{14} \mathrm{C}$ of the deeper waters remains low due to isolation from naturally occurring ${ }^{14} \mathrm{C}$ from the atmosphere as well as the bomb pulse, and in particular because it is ventilated from the Southern Ocean (Kuhlbrodt et al. 2007), which has characteristically high "reservoir ages" (Reimer and Reimer 2001; Butzin et al. 2005) resulting from the generalized upwelling of ancient deep waters along the perimeter of the Circumpolar Current.

Since the ${ }^{14} \mathrm{C}$ stations and sampling depths were not the same for the 2 cruises, we computed the difference field between the 2 cruises by first mapping each section (using Generic Mapping Tool's SURFACE; Smith and Wessel 1990) onto a $1^{\circ} \times 50 \mathrm{~m}$ rectilinear grid and then subtracting the 2 grids (presented in the third panel of Figure 2). As discussed in the previous section, analytical precision would dictate that differences of $\sim 6 \%$ on individual point comparisons are significant, with averaged differences exceeding $2 \%$ discernible at the $1-\sigma$ level. While some of the finer structure in the difference field may in part be an artifact of the gridding process, features larger than the nominal sampling and gridding resolution $\left(\sim 2^{\circ} \times \sim 100 \mathrm{~m}\right)$ are robust. The color map ranges from $-60 \%$ (blue) to $+70 \%$ (magenta) in $\Delta \Delta^{14} \mathrm{C}$. In the lowest panel of Figure 2, we show the salinity (in PSU, color map and white contours) and for reference we superimpose potential density anomaly contours (in black) on the bottom 2 panels.

Near-surface waters show a systematic decrease in $\Delta^{14} \mathrm{C}$ of approximately $30-40 \%$ between 1991 and 2005 , as would be expected from the observed $\sim 80 \%$ decline in atmospheric $\Delta^{14} \mathrm{C}$ (e.g. see Hua and Barbetti 2004; Q Hua, private communication). The negative surface anomaly penetrates more deeply in the bowl of the subtropical gyre (from approximately 45 to $25^{\circ} \mathrm{S}$ ), and also near the Antarctic Circumpolar Current $\left(\sim 56^{\circ} \mathrm{S}\right)$. The former may be rationalized on the basis of Ekman pumping driven subtropical down-welling. The latter is associated with the formation and subduction of Antarctic Mode waters, as evidenced by the penetration of low-salinity waters (e.g. McCartney 1977) depicted in the lowest panel of Figure 2.

The most striking difference, however, is the pronounced increase in $\Delta^{14} \mathrm{C}$ at intermediate depths. The anomaly appears centered on the low-salinity core of the Antarctic Intermediate Water (AAIW), and approaches $50-60 \%$ at mid-latitudes. We interpret this increase as a downstream manifestation of the evolving ${ }^{14} \mathrm{C}$ anomaly in the Antarctic Intermediate water as it circulates around the South Pacific subtropical gyre. The magnitude of this increase can be used to place rough constraints on both the transit time of freshly ventilated AAIW from the formation region to this section, and the nature of the formation process itself. Coral records show that the predominant bomb- ${ }^{14} \mathrm{C}$ response of the surface ocean was a $\sim 10$-yr step-increase that occurred between 1960 and 1970 (Druffel and Suess 1983). Comparison of the observed mid-latitude AAIW increase at this section with the coral responses in a variety of locations strongly suggests that this difference must be due to this transient. Simple one-dimensional advection-diffusion modeling demonstrates that although the magnitude and breadth (over time) of the step-change increase in ${ }^{14} \mathrm{C}$ can be affected by mixing, the advective transport of the centroid of the change is a reflection of the velocity field alone. Given that the observed increase at $150^{\circ} \mathrm{W}$ apparently occurred sometime between 1991 and 2005, we can estimate the transit time for AAIW of $33 \pm 7 \mathrm{yr}$ from the formation region (i.e. the time difference between 1965 and 1998). Iudicone et al. (2007) identify the formation and entry point of the AAIW in the 
southeastern corner of the South Pacific. A crude estimate of the path length along the gyre from this region gives $4000 \mathrm{~km}$. A transit time of $33 \mathrm{yr}$ would require a mean flow rate of approximately $4 \times$ $10^{-3} \mathrm{~m} \mathrm{~s}^{-1}$, a number qualitatively consistent with Reid's (1986) geostrophic estimates for the AAIW in this region.

We can also use the 1991 AAIW $\Delta^{14} \mathrm{C}$ observation of $-75 \%$, corrected for the transit time, to estimate a reservoir age of $600 \mathrm{yr}$ for the source waters of the AAIW. This is somewhat higher than, but not completely inconsistent with, what is obtained from inspection of the results of GCM simulations (Butzin et al. 2005). Inasmuch as AAIW is formed by deep convective events in this region (Georgi 1979; Iudicone et al. 2007), it is likely that the effective reservoir age of this water mass will be increased relative to the regional surface expression.

\section{Results and Discussion: Deep Water Changes}

The full depth ${ }^{14} \mathrm{C}$ distributions are presented in Figure 3 (upper 2 panels). They exhibit the expected large-scale ${ }^{14} \mathrm{C}$ characteristics of the abyssal South Pacific, namely a mid-depth core of low- ${ }^{14} \mathrm{C}$ water emanating from the north lying above a tongue of relatively younger $\left({ }^{14} \mathrm{C}\right.$-enriched) bottom water entering from the south. Comparison of the full depth ${ }^{14} \mathrm{C}$ differences, contoured in the third panel of Figure 3 shows a surprising large offset in the deep waters. Here again, structural details of the difference field may arise as gridding artifacts, but the overall characteristic of an average increase of 9\%o over the 2000- to 4000-m-depth range between 1991 and 2005 is highly significant relative to possible systematic uncertainties. It should be noted that the offset appears more enhanced near the bottom and less pronounced (perhaps approaching zero) at mid-depths.

The change in ${ }^{14} \mathrm{C}$ appears to be accompanied by changes in hydrography. Although not shown here, the 2005-1991 difference plots of temperature, salinity, dissolved oxygen, and silica along this section in the deep water show a weak but intriguing correlation with the larger-scale structure of the ${ }^{14} \mathrm{C}$ difference plot: higher ${ }^{14} \mathrm{C}$ areas appear associated with more saline, oxygenated, and lower silica waters, and conversely for lower ${ }^{14} \mathrm{C}$ features. Such a correlation might be expected for the intrusion of more recently ventilated waters. The $9 \%$ overall increase in abyssal ${ }^{14} \mathrm{C}$ suggests this. Calculating differences in the distribution of the Broecker et al. (1999) quantity "phosphate star" $\left(\left[\mathrm{PO}_{4}{ }^{*}\right]=\left[\mathrm{PO}_{4}\right]+\left[\mathrm{O}_{2}\right] / 175-1.95 \mu \mathrm{mol} \mathrm{kg}^{-1}\right)$ reveals a slight elevation of approximately $0.03 \mu \mathrm{mol}$ $\mathrm{kg}^{-1}$ in the abyss north of $45^{\circ} \mathrm{S}$. An increase in $\left[\mathrm{PO}_{4}{ }^{*}\right]$ combined with elevated ${ }^{14} \mathrm{C}$ is consistent with an elevated contribution of a "northern source" water (North Atlantic Deep Water) relative to Southern Ocean sources of deep water in the Pacific.

\section{SUMMARY AND CONCLUSIONS}

We report a comparison of ${ }^{14} \mathrm{C}$ and hydrographic measurements made along $150^{\circ} \mathrm{W}$ in the South Pacific in 1991 and 2005. The shallow water ${ }^{14} \mathrm{C}$ patterns show the expected decrease to lower values associated with the atmospheric decline in the bomb ${ }^{14} \mathrm{C}$ transient. The Antarctic Intermediate Waters show a dramatic $50-60 \%$ increase in $\Delta^{14} \mathrm{C}$ at mid-latitudes, which we attribute to a downstream manifestation of the 1960 s oceanic transient response to the atmospheric ${ }^{14} \mathrm{C}$ peak. This allows us to estimate a transit time of order 3 decades between the AAIW formation region and this section, corresponding to advection speeds of order $4 \times 10^{-3} \mathrm{~m} \mathrm{~s}^{-1}$. The deep waters show a modest but surprising increase in ${ }^{14} \mathrm{C}$ over the intervening years. This increase appears to coincide with small increases in salinity and dissolved oxygen, and a small decrease in dissolved silica. The fact that these are also accompanied by small increase in $\left[\mathrm{PO}_{4}{ }^{*}\right]$ is suggestive of a shift toward North Atlantic Deep Waters as a source of ventilating waters for the Pacific, consistent with the speculation by Broecker et al. (1999) of possible recent changes in the nature of the global conveyor. The 


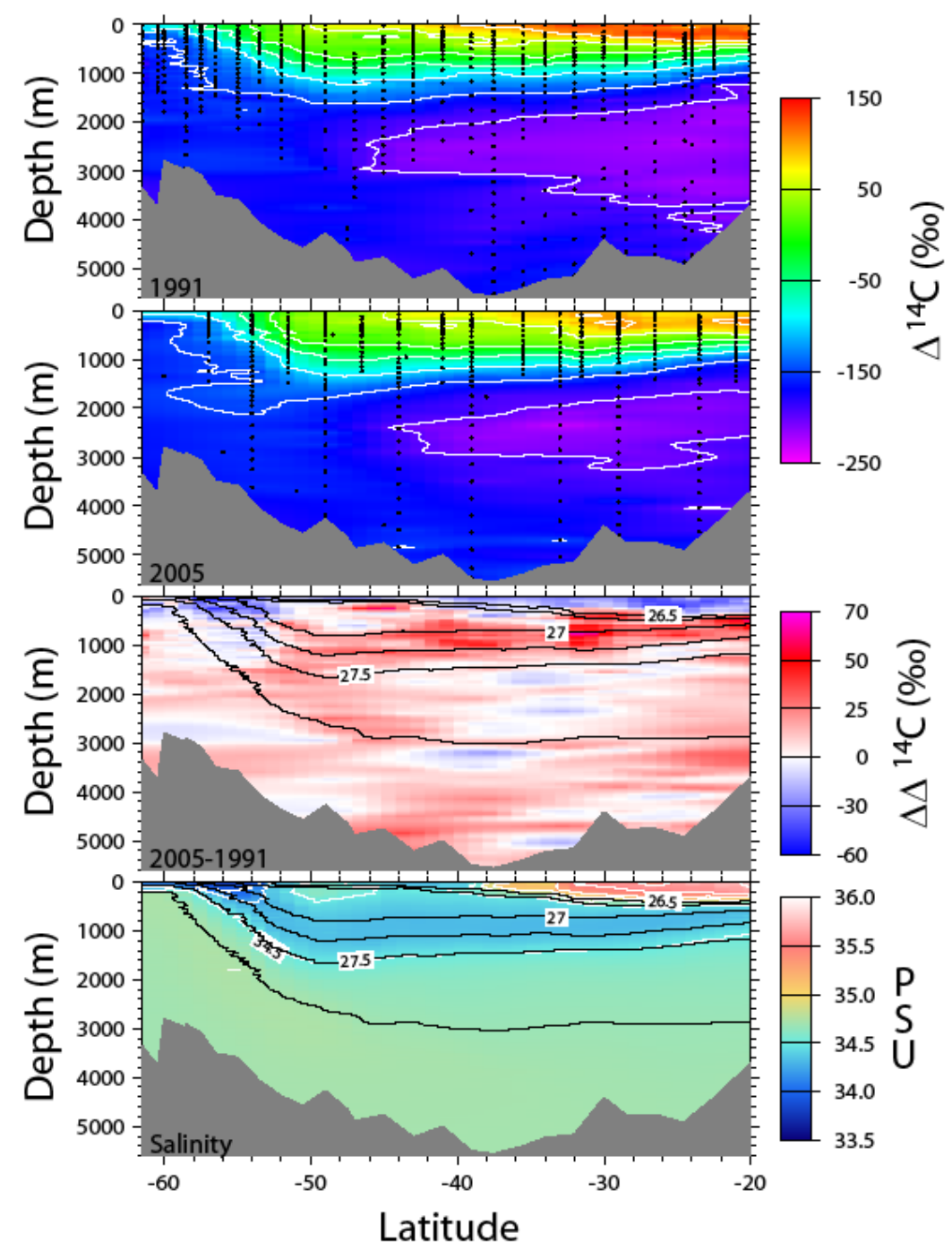

Figure 3 Full depth contour plots (latitude versus depth) of the distribution of $\Delta^{14} \mathrm{C}$ in 1991 (upper panel) and 2005 (second panel from top), and the difference (2005-1991) between the gridded fields (third panel from top), all in \%. Sample locations are indicated by black dots in the upper 2 panels. The lowest panel shows the contoured salinity distribution (color map and white contours). The potential density anomaly (in $\mathrm{kg} \mathrm{m}^{-3}$ ) is overlaid as black contours on the lower 2 panels.

changes are statistically significant but nonetheless subtle and circumstantial. However, they point to the value both of ${ }^{14} \mathrm{C}$ as a diagnostic of ocean ventilation, and of repeat measurements over the coming decades.

\section{ACKNOWLEDGMENTS}

This work was performed under National Science Foundation Grant number OCE-0223434 as well as a cooperative agreement with NSF (most recently OCE-0228996). We are grateful to the Chief Scientists on the WOCE and CLIVAR expeditions, the marine technicians, and the hardworking staff at the National Ocean Sciences AMS Facility. 


\section{REFERENCES}

Bainbridge AE, Ostlund HG, Craig H, Broecker WS, Spencer DW. 1987. GEOSECS Atlantic, Pacific, and Indian Ocean expeditions: shore-based data and graphics. GEOSECS ATLAS, 7. $200 \mathrm{p}$.

Broecker WS, Peng T-H. 1980. The distribution of bombproduced tritium and radiocarbon at GEOSECS station 347 in the eastern North Pacific. Earth and Planetary Science Letters 49(2):453-62.

Broecker WS, Peng T-H, Ostlund HG, Stuiver M. 1985. The distribution of bomb radiocarbon in the ocean. Journal of Geophysical Research 90(C90):6953-70.

Broecker WS, Sutherland S, Peng T-H. 1999. A possible 20th-century slowdown of Southern Ocean deep water formation. Science 286(5442):1132-5.

Broecker WS, Sutherland SC, Smethie WM, Peng T-H, Ostlund HG. 1995. Oceanic radiocarbon: separation of the natural and bomb components. Global Biogeochemical Cycles 9(2):263-88.

Butzin M, Prange M, Lohmann G. 2005. Radiocarbon simulations for the glacial ocean: the effects of wind stress, Southern Ocean sea ice and Heinrich events. Earth and Planetary Science Letters 235(1-2):45-61.

Craig H. 1969. Abyssal carbon and radiocarbon in the Pacific. Journal of Geophysical Research 74(23): 5491-506.

Doney S, Hecht MW. 2002. Antarctic Bottom Water formation and deep-water chlorofluorocarbon distributions in a global ocean climate model. Journal of Physical Oceanography 329(6):1642-66.

Druffel EM, Suess HE. 1983. On the radiocarbon record in banded corals: exchange parameters and net transport of ${ }^{14} \mathrm{CO}_{2}$ between atmosphere and surface ocean. Journal of Geophysical Research 88(C2):1271-80.

Elder KL, McNichol AP, Gagnon AR. 1998. Evaluating reproducibility of seawater, inorganic and organic carbon ${ }^{14} \mathrm{C}$ results at the National Ocean Sciences AMS Facility (NOSAMS). Radiocarbon 40(1):223-30.

England MH, Maier-Reimer E. 2001. Using chemical tracers to assess ocean models. Reviews of Geophysics 39(1):29-70

Georgi DT. 1979. Modal properties of Antarctic Intermediate Water in the Southeast Pacific and the South Atlantic. Journal of Physical Oceanography 9(3):456-8.

Hua Q, Barbetti M. 2004. Review of tropospheric bomb ${ }^{14} \mathrm{C}$ data for carbon cycle modeling and age calibration purposes. Radiocarbon 46(3):1273-98.

Iudicone D, Rodgers KB, Schopp R, Madec G. 2007. An exchange window for the injection of Antarctic Intermediate Water into the South Pacific. Journal of Physical Oceanography 37(1):31-49.

Jenkins WJ, Rhines PB. 1980. Tritium in the deep North Atlantic Ocean. Nature 286(5776):877-80.

Key RM. 1996. WOCE Pacific Ocean radiocarbon program. Radiocarbon 38(3):415-23.

Key RM, Quay P, Jones GA, McNichol AP, von Reden K, Schneider RJ. 1996. WOCE AMS radiocarbon I: Pa- cific Ocean results (P6, P16 and P17). Radiocarbon 38(3):425-518.

Key RM, Quay P, Schlosser P, McNichol AP, von Reden K, Schneider B, Elder KL, Stuiver M, Ostlund HG. 2002. WOCE Radiocarbon IV: Pacific results; P10, P13N, P14C, P18, P19 \& S4P. Radiocarbon 44(1): 239-392.

Kuhlbrodt T, Griesel A, Montoya M, Levemann A, Hofmann M, Rahmstorf S. 2007. On the driving processes of the Atlantic meridional overturning circulation. Reviews of Geophysics 45: RG2001, doi:10.1029/ 2004RG000166.

Liu Z, Alexander M. 2007. Atmospheric bridge, oceanic tunnel, and global climate teleconnections. Reviews of Geophysics 45: RG2005, doi:10.1029/ 2005RG000172.

Mahadevan A. 2001. An analysis of bomb radiocarbon trends in the Pacific. Marine Chemistry 73(3-4):27390.

McCartney MS. 1977. Subantarctic mode water. In: Angel M, editor. A Voyage of Discovery. Oxford: Pergammon Press. p 103-19.

McCreary JP, Lu P. 1994. Interaction between the subtropical and equatorial ocean circulations: the subtropical cell. Journal of Physical Oceanography 24(2): 466-97.

McNeil BI, Matear RJ, Key RM, Bullister JL, Sarmiento JL. 2003. Anthropogenic $\mathrm{CO}_{2}$ uptake by the ocean based on the global chlorofluorocarbon data set. Science 229(5604):235-9.

McNichol AP, Gagnon AR, Jones GA, Osborne EA. 1992. Illumination of a black box: analysis of gas composition during graphite target preparation. $R a$ diocarbon 34(3):321-9.

McNichol AP, Jones GA, Hutton DL,Gagnon AR. 1994. The rapid preparation of seawater $\Sigma \mathrm{CO}_{2}$ for radiocarbon analysis at the National Ocean Sciences AMS Facility. Radiocarbon 36(2):237-46.

Munk WH. 1966. Abyssal recipes. Deep-Sea Research 13:707-30.

Ostlund HG, Dorsey HG, Rooth CG. 1974. GEOSECS North Atlantic radiocarbon and tritium results. Earth and Planetary Science Letters 23(1):69-86.

Reid JL. 1986. On the total geostrophic circulation of the South Pacific Ocean: flow patterns, tracers and transports. Progress in Oceanography 16(1):1-61.

Reimer PJ, Reimer RW. 2001. A marine reservoir correction database and on-line interface. Radiocarbon 43(2A):461-3.

Rodgers KB, Aumont O, Madec G, Menkes C, Blanke B, Monfray P, Orr JC, Schrag D. 2004. Radiocarbon as a thermocline proxy for the eastern equatorial Pacific. Geophysical Research Letters 31: L14314, doi: 10.1029/2004GL019764.

Rubin SI, Key RM. 2002. Separating natural and bombproduced radiocarbon in the ocean: the potential alka- 
linity method. Global Biogeochemical Cycles 16(4): 1105, doi:10.1029/2001GB001432.

Schlosser P, Bullister JL, Fine RA, Jenkins WJ, Key RM, Lupton JE, Roether W, Smethie WM. 2001. Transformation and age of water masses. In: Siedler G, Church J, Gould J, editors. Ocean Circulation and Climate: Observing and Modelling the Global Ocean. International Geophysics Series. San Diego: Academic Press. p 431-52.

Scott EM, Bryant C, Cook GT, Naysmith P. 2003. Is there a Fifth International Radicarbon Comparison (VIRI)? Radiocarbon 45(3):493-5.
Smith WHF, Wessel P. 1990. Gridding with continuous curvature splines in tension. Geophysics 55(3):293305.

Stuiver M, Polach HA. 1977. Discussion: reporting of ${ }^{14} \mathrm{C}$ data. Radiocarbon 19(3):355-63.

Vogel JS, Southon JR, Nelson DE. 1987. Catalyst and binder effects in the sues of filamentous graphite for AMS. Nuclear Instruments and Methods in Physics Research B 29(1):50-6.

Waugh DW, Hall TM, McNeil BI, Key RM, Matear RJ. 2006. Anthropogenic $\mathrm{CO}_{2}$ in the oceans estimated using transit time distributions. Tellus B 58(5):376-89. 